\title{
Collaborative Group Support in e-Health
}

\author{
Paulo Novais and Ângelo Costa \\ DI-CCTC \\ Universidade do Minho \\ Braga, Portugal \\ Email: pjon,acosta@di.uminho.pt
}

\author{
Ricardo Costa and Luís Lima \\ CIICESI, Escola Superior de Tecnologia e Gestão de Felgueiras \\ Instituto Politécnico do Porto \\ Felgueiras, Portugal \\ Email: rcosta,llima@estgf.ipp.pt
}

\begin{abstract}
In critical areas such as decision making, the Collaborative Work has an uttermost importance. Being a complex problem, the collective decision taking is currently a popular form of taking decisions. In this work we present the VirtualECare project: an intelligent multi-agent system able to monitor, interact and serve its customers (in need of care services). In developed countries, recent census data report a sudden increase in the elderly community together with a decrease of child birth. This is a new reality that needs to be dealt by the health sector, particularly by the public one. In an early stage, this new situation appears mostly as a financial problem. The costs involved in the health care are considerable. Thus, alternative technological solutions that lead to straightforward solutions should be adopted. Recently, a growing interest in combining the advances in information society - computing, telecommunications and presentation - to create Group Decision Support Systems (GDSS), has been observed. It is our view that the use of the GDSS in the health care area will pursue the achievement of better results in terms of patients Electronically Clinical Profile (ECP). Additionally, we believe that the best way of managing health appointments is through the use of calendars - one application that can manage both the physicians and patients calendars and consequently their day schedule. Within this area, the approaches used in the VirtualECare and iGenda projects are presented.
\end{abstract}

Index Terms-Keywords-component; Group Support; e-Heath; Collaborative Networks

\section{INTRODUCTION}

As the human population is ageing, it is a matter of fact that the elderly in need of special attention is also growing.

Old age brings new problems (e.g., health, loneliness), aggravated with the lack of specialized human resources to assist their needs. However, this is not exclusive of the elderly, as diseases like obesity, diabetes, and blood pressure have been increasing among young adults [1]. As a new reality, it has to be dealt by the health sector, and especially by the public one. Thus, the importance of finding new and cost effective ways for health care delivery are of particular importance, especially when one wants them not to be re-moved from their "habitat" [2].

Besides that fact, pressures exist in government and society (e.g., budgetary restraints, cost of medical technologies and cost of internment) that will force readjustments of actual health care practice, which may also affect other co-related public systems [3], [4].

\section{A. Motivation}

In the last years we have assisted to a proliferation of various research projects in order to increase the quality of care services and reduce the associated costs, especially the ones that require the patient to be de-localized from his natural habitat (Home). Normally these tend to be simple and basic reactive alarm systems without many requirements from the support platform point of view [5]. In our opinion these systems were very useful to delineate a path for others to follow. Taking this path we have presented the VirtualECare project [6], [7] which we believe will be the next generation of remote proactive healthcare system with, in our case, Group Decision techniques for problem solving through the use of to-day's available, low cost, technology making this way a very promising approach to a possible solution for some of the health sector problems.

\section{THE VIRTUALECARE PROJECT}

Our objective is to present an intelligent multi-agent system not only to monitor and to interact with its costumers (being those elderly people or their relatives), but also to be interconnected to other computing systems running in different healthcare institutions, leisure centres, training facilities or shops. The VirtualECare [8] architecture is a distributed one, being their components unified through a network (e.g., LAN, MAN, WAN), and each one with a different role (Fig.1).

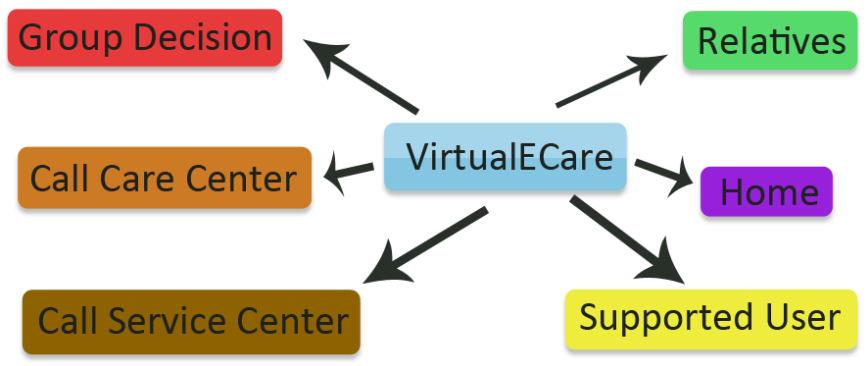

Fig. 1. VirtualECare

\section{COLLABORATIVE NETWORKS IN DIGITAL HOMECARE}

The use of collaborative networks in the care of the elderly may be an important part of a social development process, 
yet it has not been studied in depth. This work looks at the role that collaborative networks and learning plays within the innovative processes of a smart home for care of the elderly, and suggests a framework that will allow an organization to strategically model a collaborative environment that may be conducive to innovation. Such a framework will identify key areas of the Inter-Virtual Organizations Co-operation for Care of the Elderly, which should be discussed in line with the collaborative tool requirements of the care providers. A theoretical ontology based tool is also briefly discussed to capture and identify how the services of the elderly project team are innovating and provide care providers with collaborative tools, which will reflect their collaborative and knowledge needs.

Some work on the above problem has been made, namely using alarm systems that can be triggered by the monitored people in case of necessity, to more modern ones, using almost any artifacts that the new technologies have to offer [4], [10].

The major goal in our work is to take the work already done to a next level, enhancing elderly quality of life [3]. The path to pursue relies on a mix of different contributions from Artificial Intelligence, such as Collaborative Networks, Ambient Intelligence and Knowledge Representation tools coupled whit different computational paradigms and methodologies for problem solving, such as Agent Based Systems and Group Decision Support Systems. To achieve such a result, we will enrich any space (e.g., houses, buildings, critical areas in hospitals) with smart artifacts so that through the use of automated or semi-automated Group Decision Support Systems we may diagnose healthcare problems (and more) and present solutions on time [11].

The challenges faced by both business and academy in recent years, in association with the advances in information and communication technology, lead to the creation of a large variety of Networks, namely Collaborative Networks $(\mathrm{CN})$. Basically, $\mathrm{CN}$ let professionals and organizations to seek complementary and joint activities, allowing them to participate in new and more competitive businesses opportunities, reaching new markets and/or fostering scientific excellence, either in forms of services or products. This can be done, namely, through highly integrated supply chains, virtual enterprises/organizations, professional virtual com-munities, value constellations and/or virtual laboratories [12].

\section{GROUP DECISION SUPPORT SYSTEM}

By definition, any Collaborative Network Organizations (CNO) has to support collaborative work that presupposes the existence of a group of people that has as mission the completion of a specific task [13]. The number of elements involved in the group may be variable, as well as the persistency of the group. The group members may be at different places, meet in an asynchronous way or may belong to different organizations. Collaborative work has not only inherent advantages (e.g., greater pool of knowledge, different world perspectives, increased acceptance), but also assertive goals (e.g., social pressure, domination, goal displacement, group thinking) [14].
Group Support Systems (GSS) intend, as we shall see, to support collaborative work. In this work we will call "meeting" to all the processes necessary to the completion of a specific collaborative task. A meeting is a consequence or an objective of the interaction between two or more persons [15]. Physically, a meeting can be realized in one of the four scenarios: same time / same place, same time / different places, different times / same place and different times / different places. Each one of these scenarios will require from the GSS a different kind of support.

Until now we discussed collaborative work and present group members as the only persons involved in the process. However, it is very common to see a third element taking part in the course of action, the facilitator. The meeting facilitator is a person welcomed by all the members of the group, neutral and without authority to make decisions, which intervenes in the process in order to support the group in the identification of a problem and in the finding of a solution, in order to increase group efficiency [16]. According to Dubs and Hayne [17] a meeting has three distinct phases, as it is depicted in Figure 2.

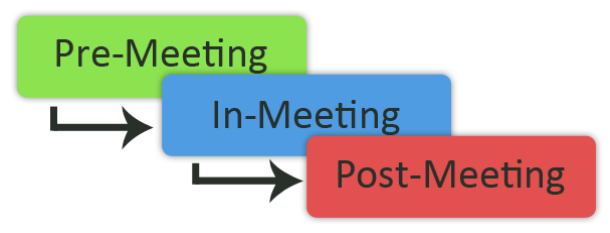

Fig. 2. Meeting phases

In the Pre-Meeting phase the facilitator prepares the meeting, i.e., establishes the meeting goals, proceeds with the group formation (making sure that all the participants have the necessary background), selects the best supporting tools, in-forms the meeting members about the goals and distributes among them the meeting materials.

In the In-Meeting phase the participants will be working in order to accomplish the meeting goals, and the facilitator has the task of monitoring the meeting inter-actions (e.g., to observe the relationship between the group members) and to intervene if necessary.

In the Post-Meeting phase, it is important to evaluate the results achieved by the group, as well as by how much each group member is acquit with the achieved results (satisfied/unsatisfied). Still, in this phase it is very important to identify and store information that can be useful in future meetings (e.g., how to actualize the participant's profile for future selection).

\section{RECOMMENDATION SYSTEM}

\section{A. Idea Generation}

The Group Decision module, as it was said before, is a major module of our system. This fact, associated with the importance of decision-making in today business activity and with the needed celerity in obtaining a decision in the majority of the cases that this key module will be defied to 


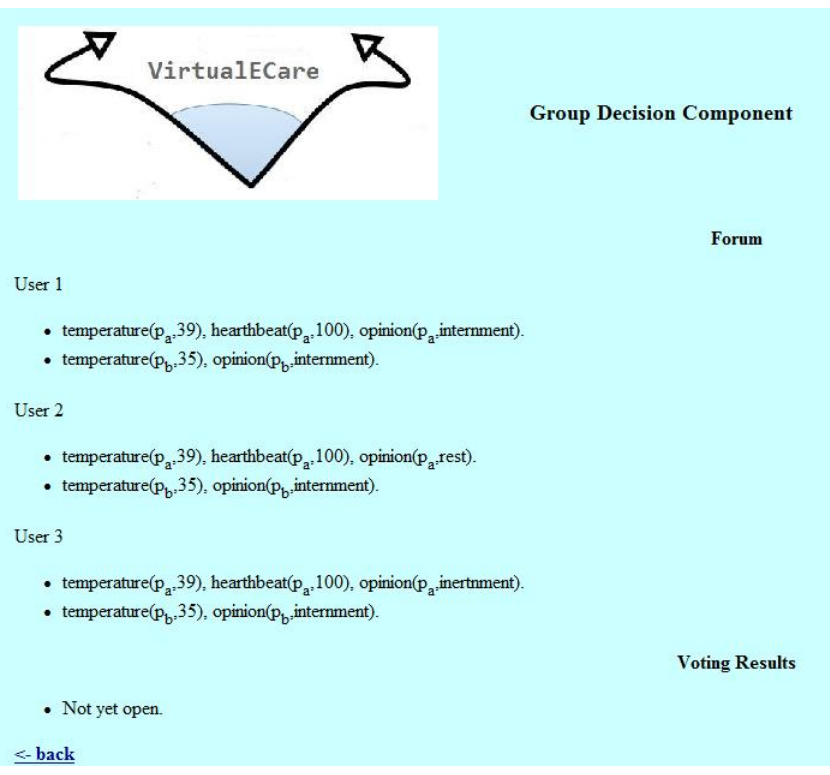

Fig. 3. VirtualECare forum

resolve, requires a real effectiveness of the decision making process. Thus, the need for an Idea Generation tool that will support the meetings, being those face-to-face, asynchronous or distributed, becomes crucial.

The flow of new ideas is central in an environment as the one presented above. Several idea generation techniques were popularized during the early 1950's in order to assist organizations to be fully innovative. These techniques, although primarily born and used in the advertising world, can be applied to an infinite number of emerging areas. Many idea techniques emerged from that time and continue to current days, such as Brainstorming, Nominal Group Technique (NGT), Mindmapping and SCAMPLER, among others.

In order to face the real challenges that this module have to deal with, we selected two idea generation techniques for different situations:

Brainstorming - it is probably the best-known creative tool. It can be used in most groups, although in most cases the rules that oversee it must be perceived by the group elements. It comes with all its potential when and independent facilitator manages the process (so the group can focus on the creative tasks). Normally, a brainstorming has duration somewhere between 30 minutes to 1 hour, depending on the difficulty of the problem and the motivation of the decision group. Due to this fact it cannot be used in situations of life or death, but it can and is going to be used in assessing patient's quality of life;

Mind-mapping - it is best used when one needs to explore and/or develop ideas for a specific problem, or when we need to take notes and/or summarize meetings. It can be used to obtain immediate answers in critical situations.

In Mind-mapping the specific problem is presented in the form of a decision tree, being the vital data obtained, for instance, from the sensors attached to the Supported User
(Figure 4).

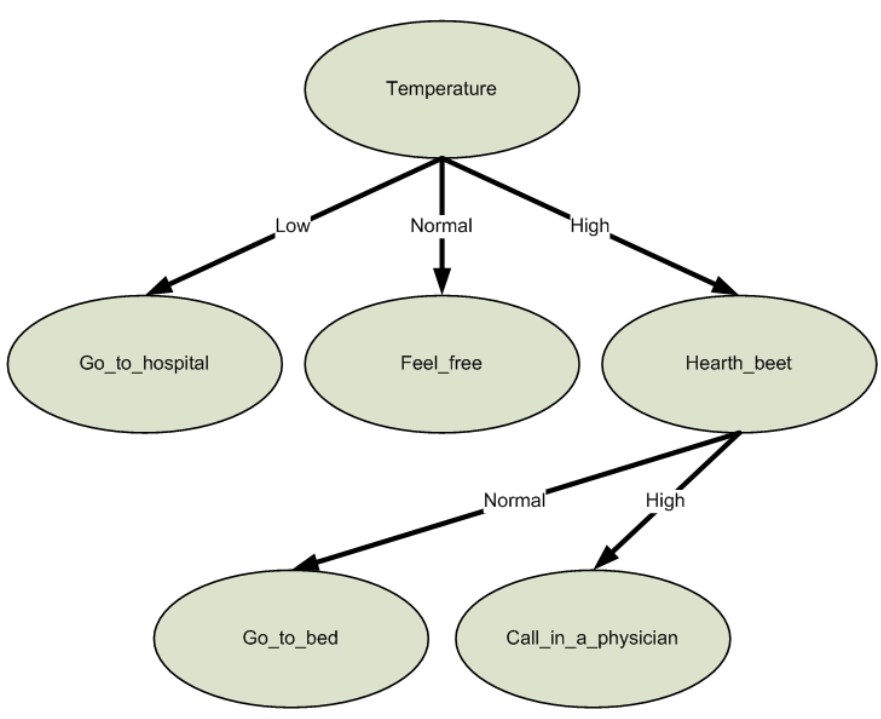

Fig. 4. A decision tree of a specific problem

\section{B. Argumentation}

After establishing individual ideas (through the above presented tools, or simply by intuition) the participants are expected to "defend" those ideas in order to reach consensus or majority. Each participant will, therefore, and in a natural way, argue for the most interesting alternatives or against the worst alternatives, accord-ing to his/her preferences and/or skills. By expressing their arguments, participants expect to influence the others' opinions and make them change their own [19].

This module is based on the IBIS (Issue Based Information System) argumentation model developed by Rittel and his colleagues in the early 70's [20]. The core of this methodology is based on the matrix of questions, ideas and arguments that, all combined, represent a dialogue. According to this model, an argument is a statement or an opinion that may support or pointed out one or more ideas.

Among the three elements of the IBIS model, there exists nine possible links, as it is depicted in Figure 5.

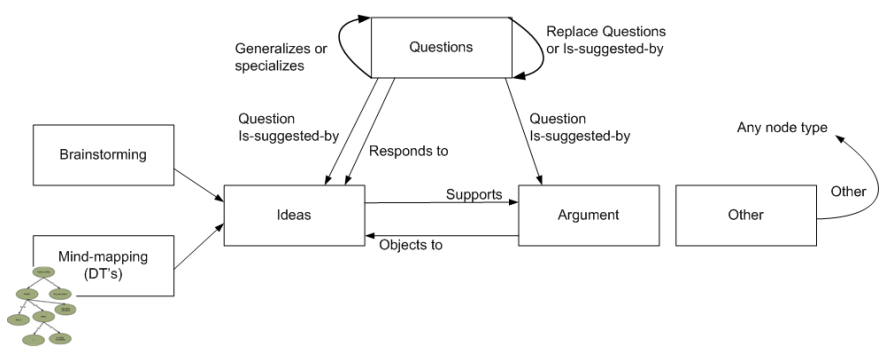

Fig. 5. IBIS model adapted from Conklin and Begeman

In the implementation process of the Group Decision apparatus, and the respective support software, some modifications to the model have been made.

The question in the IBIS model is, in the Group Decision apparatus, the goal of the meeting. Ideas are the alternatives 
of the multi-criteria decision problem and arise from the idea generation tool throughout brainstorming or through mind mapping.

Arguments in IBIS can be pros or cons vis-?is a given idea. In the Group Decision module they are based in two types of information: Patient Electronic Clinical Profile and a set of Decision Trees. Additionally, the possibility for one participant to argue using an argument from another member is real.

This module is paramount on the in-meeting phase. It is used by the participants to defend their positions, but can also be used in the post-meeting phase by the facilitator (e.g. if the group does not reach a solution, the facilitator may use this module to check which is the most consensual alternative).

The IBIS model has been often used in the development of GDSSs, the first implementation being gIBIS [21]. By adopting this model, the Group Decision module should enable a better organization of the arguments exchanged by the participants. This may facilitate opinion convergence, and at the same time to re-duce the meetings "noise".

Once a decision has been made, it is (automatically) sent to the monitored per-son (Supported User in Figure 1) by a mobile device (Figure 5), in order to keep him/her informed.

\section{MEMORY ASSISTANT}

Aiming to help both the user and the physicians involved in the GDSS, a memory assistant is the best tool to keep track of all the problems. Due to its modularity the memory assistant can serve both the user by reminding the basic events or chained events to the physician.

By definition a memory assistant is an person or device that helps a selected user to remember or recollect the saved memories or events.

The iGenda project is, defined by the previous statement, a Personal Memory Assistant. It has a user/physician support and a Centralized Memory System (CMS) support [22]. It objectively manages a full range of services of a mindmapping system in the form of an intelligent events scheduler.

In the scenario presented on this document the typical form of functioning is firstly the memory assistant reminds the physician that there is a meeting to attend at a certain hour. This warning is propagated through the several persons that are involved in the meeting. To each person personalized notes can be stored and showed to the user when he wants to. These notes can be edited and rewritten.

In terms of the initial schedule of the meeting it should be reached into a consensus between the several persons involved. In case that consensus cannot be achieved the system can reach a compromised, it scans the all of the physicians calendar and find an available space (paying attention to certain boundaries). The compromised shared calendar can be flexible in case of the involved physicians to not have a common free space. In this case it is flagged the best possible compromise between all persons, it is taken into account factors like importance of the events in paramount and the best combination to affect the least persons possible. Mind the fact that time space to do the meeting is ever so crucial, relating the patients in cause.
After the meeting and reached to a conclusion the solution is transmitted back to the CMS, it than charges to process and mark the decisions. Several decisions can be taken during the meeting, being most of them sub-factors of the following main decisions:

- Another visit of the patient - The patient should present himself to a new consult to be verified his health condition by a doctor.

- Schedule a new reunion - The monitored data of the patient is inconclusive and the best solution is to collect more data and do a new session.

- Change the current medication and collect new data The patient is informed that the current medical treatment is not working as it should and a new prescription is available to him to follow.

After the main decision the User/Patient is notified of the new decision, if that is the case, because some decisions do not require the knowledge of the patient. The patient is notified mainly by the iGenda platform. In case of a new visit or the change of the medication the information is directly relayed to the patient calendar. The warning system can take several forms, but in case of the medication the best approach is to put a phone operator to call to the patient and orally inform him that the medication is changed and that he should direct himself to an pharmacy or that someone is taking them to his house.

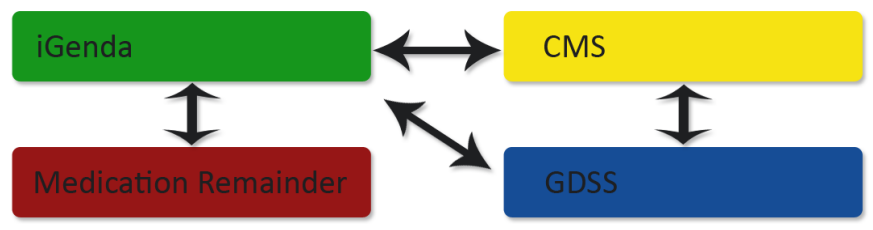

Fig. 6. Main modules structure

The principal way of communication of the iGenda is a PDA. This solution is ideal because the connectivity and portability that is most desired. It goes also in the guides of the operation of the meeting of the Group Decision. The multiple functionalities available by that device are immense and nowadays can be truly a personal computer replacement. The processing capacity although limited it is more than necessary because all the conflicts are solved in the main server and the solution is then sent to the user.

\section{A. User functionalities}

The iGenda has two main functionalities available to the user. The Conflicts Resolution Manager (CM) and the Free Time Manager (FTM).

The CM work in the way that we can try or, if configured to do it so, resolve all the conflicts. With the use of conflict resolution algorithms the possible paramount is resolved with the following terms:

- Level of importance between the both events.

- By medical request and/or the communication between the physicians, and 
- By the user choice.

In terms of overlapping of events with different levels the iGenda replaces immediately the least important and tries initially to reschedule the event if it is not possible to do it so the event is eliminated and a notification is sent to the user. The iGenda supports also shared calendar, where different persons can share the same activities, in case of conflict of shared activities the users are notified of the alteration or the remove of the activity.

The FTM is an activities enabler, that schedules playful activities. These activities move towards the implementation of an active life. This active life is a great feature, because gives meaning and purpose to the user's life. The activities can the solitaire or integrated in a community of persons. The FTM is linked to a database that has the activities the user most fancies. For the community enable activities it has to be manually schedule. The activities are automatically configured to be scheduled in predefined spaces of time.

It remains to the user to execute them or not, as it is only a suggestion system but we do think that it is of the most importance to the user to execute the activities.

As stated before the best way of communication it trough an mobile device, a PDA. It is also being prepared several other means of communication, such as voice recorded messages and SMS messages.

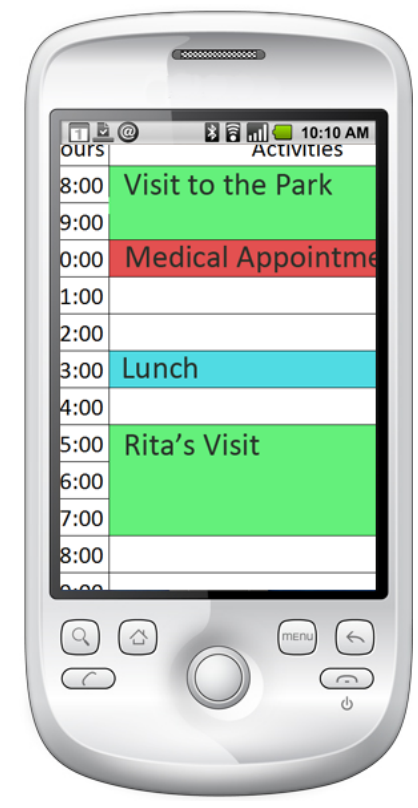

Fig. 7. PDA Mockup of the iGenda calendar

\section{CONCLUSION AND FUTURE WORK}

The new reality in the healthcare sector to allow a dignified care provisioning to all the population in general, and the elderly in particular imposes new approaches to provide specialized services, without de-localizing or messing up with their routines, in a more effective and intelligent way. This paper presents the VirtualECare project with special incidence on the Group Decision module that supports asynchronous and distributed meetings set up for solving multi-criteria decision problems. The system supports the meeting participants in constructing and sharing ideas and "defends" those ideas in order to reach consensus or majority. To defend his ideas, each participant, should argue for the most interesting alternatives or against the worst alternatives, according to his/her preferences and/or skills, expecting to influence the others' opinions and make them change their own. The argumentation module will allow not only a simple way of justifying opinions, but also a persuasive argumentation in order to allow each element to try influence other through the confrontation of opinions.

Additionally, we are going to apply Knowledge Representation with the respective Quality of its Information to the Group Decision module. Thus, the suggestions/decisions presented by this module, will consider the existence of in-complete information, and, even so, will present a possible way to try and, if possible, resolve the actual problem. Incomplete information may arise from several sources (e.g. unreachable sensors, incomplete Patient Electronic Clinical Profile), but what is important is to be able to measure the quality of the information we have access to and the quality of the ideas presented by the participants, based in factors like reputation, credibility, namely, in the discussion. However, we are certain, that some vital information, if incomplete, may even so, compromise any suggestion/decision but, in the majority of situations, we believe this will not be the case.

This paper presents also the iGenda project. The iGenda started as a module of the VirtualECare project but grew larger and as the potentialities were revealed, the project became independent and self-aware. The iGenda tends to the a life changing tool to the user and a important daily work activities organizer. It can be seen by the hospital as a resources optimizer and planner, allowing to improve the work routines of the physicians. In the case of the iGenda although most of the implementation is done there is still many things to be done. As it can be seen in the case of the PDA implementation that is still in coding phase.

In future work, we expect to elaborate on real life scenarios and situations, in order to make the necessary's developments to set a working prototype, that could provide to the population in general, and the elderly, in particular, a certain amount of remote services (e.g., healthcare, entertainment), without delocalizing or messing up with their routines, in a more effective and intelligent way.

Attending to the presented scenarios and a possible ways to make it reality, we present how we may use collaborative networks as a support for different, but interconnected virtual organizations, that could provide to all the population in general, and the elderly, in particular way, a certain amount of remote services (e.g. healthcare, entertainment, learning), without delocalizing or messing up with their routine, in a more effective and intelligent way. 


\section{REFERENCES}

[1] E. S. Ford and S. Capewell, "Coronary Heart Disease Mortality Among Young Adults in the U.S. From 1980 Through 2002: Concealed Leveling of Mortality Rates," JACC, pp. 2128-2132, 2007.

[2] WHO, "Active ageing: towards age-friendly primary health care," World Health Organization2004.

[3] M. Gir?ez and C. Casal, The Role of Ambient Intelligent in the Social Integration of the Elderly: IOS Press, 2005.

[4] L. M. Camarinha-Matos and H. Afsarmanesh, Virtual Communities and Elderly Support: WSES, 2001.

[5] N. Saranummi, et al., "Ageing \& Technology - State of the art," Report for the European Commission, Institute for Prospective Studies, Seville, SpainNovember 1996.

[6] Novais P., Costa R., Carneiro D., Neves J., Inter-Organization Cooperation for Ambient Assisted Living, in Journal of Ambient Intelligence and Smart Environments, IOS Press 2010 (to appear).

[7] Costa R., Neves J., Novais P., Machado J., Lima L. and Alberto C., Intelligent Mixed Reality for the Creation of Ambient Assisted Living, in Progress in Artificial Intelligence, Neves J., Santos M. and Machado J. (eds), Lecture Notes in Artificial Intelligence 4874 Springer, ISBN 978-3-540-77000-8, 2007.

[8] Costa R., Novais P., Lima L., Carneiro D., Samico D., Oliveira J., Machado J. and Neves J., VirtualECare: Intelligent Assisted Living, in Electronic Healthcare, Dasun Weerasinghe (ed.), Springer-Verlag, Series Institute for Computer Sciences, Social Informatics and Telecommunications Engineering, pp 138-144, ISBN 978-3-642-00412-4, (Revised Selected Papers of The 1st International Conference on Electronic Healthcare in The 21st Century, City University, London, England, in September 8 - 9, 2008), 2009.

[9] S. Holmlid and A. Bj?lind, "Ambient Intelligence to Go," 2003.

[10] A. Sarela, et al., "IST Vivago?- an intelligent social and remote wellness monitoring system for the elderly," in 4th International IEEE EMBS Special Topic Conference on Information Technology Applications in Biomedicine, Birmingham, UK, 2003, pp. 362-365.

[11] J. C. Augusto, et al., "Enhanced Healthcare Provision Through Assisted Decision-Making in a Smart Home Environment," in 2nd Workshop on Artificial Inteligence Techniques for Ambient Inteligence, 2007.

[12] L. M. Camarinha-Matos, Virtual Enterprises and Collaborative Networks (IFIP International Federation for Information Processing): Kluwer Academic Publishers, 2004.

[13] L. Camarinha-Matos, "New collaborative organizations and their research needs," in PRO-VE'03, 2003.

[14] G. Marreiros, et al., "Ambient Intelligence in Emotion Based Ubiquitous Decision Making," in Proceedings of the International Joint Conference on Artificial Intelligence (IJCAI 2007) - 2nd Workshop on Artificial Intelligence Techniques for Ambient Intelligence (AITAmI'07), 2007.

[15] R. Bostrom, et al., Eds., Group facilitation and group support systems (Group Support Systems: New Perspectives. Macmillan, 2003

[16] R. M. Schwarz, The Skilled Facilitator: Practical Wisdom for Developing Effective Groups: Jossey Bass, 1994.

[17] S. Dubs and S. C. Hayne, "Distributed facilitation: a concept whose time has come?," presented at the Computer Supported Cooperative Work, 1992.

[18] H. Rittel and M. Webber, "Dilemmas in a General Theory of Planning," Policy Sciences, vol. 4, pp. 155-169, 1973.

[19] L. Brito, et al., "The logic behind negotiation: from pre-argument reasoning to argument-based negotiaion," in Intelligent Agent Software Engineering, V. Plekhanova, Ed., ed: Idea Group Piblishing, 2003, pp. $137-159$.

[20] J. Conklin, "The IBIS Manual: A short course in IBIS methodology," GDSS Inc.

[21] J. Conklin and M. Begeman, gIBIS: A Hypertext tool for exploratory policy discussion vol. 6, 1988 .

[22] Costa A., Novais P., Costa R., Corchado J.M., Neves J., Multi-Agent Personal Memory Assistant, PAAMS 10 - The 8th International Conference on Practical Applications of Agents and Multi-Agent Systems, University of Salamanca, Spain, 26-28th April, 2010 (To appear). 